\title{
Gladius and its derivatives as potential biosorbents for marine diesel oil
}

\author{
Mayra F. Preto $^{1} \cdot$ Sérgio P. Campana-Filho ${ }^{2}$ - Anderson Fiamingo ${ }^{2}$. \\ Ivana C. Cosentino $^{3}$ - Maria C. Tessari-Zampieri ${ }^{3}$ - Denis M. S. Abessa ${ }^{1}$. \\ Ágata F. Romero ${ }^{1}$ - Isabella C. Bordon ${ }^{1}$
}

Received: 20 June 2017 / Accepted: 10 August 2017 / Published online: 16 August 2017

(C) Springer-Verlag GmbH Germany 2017

\begin{abstract}
The demand for low cost and effective materials to remove contaminants such as residues of oil spills has encouraged studies on new biosorbents produced from wastes. Considering the overgeneration of fishing residues and the necessity to provide an alternative purpose for such materials, this study aimed to evaluate squid gladius and its derivatives ( $\beta$-chitin and chitosan) as sorbents to remove marine diesel oil (MDO) from fresh and artificial seawater. It was also executed an attempted to improve their performances through a highintensity ultrasound treatment (UT-gladius and UT- $\beta$-chitin). All sorbents removed MDO at both salinities. Contact surface area, salinity, and water retention seemed to play a key role in the outcomes. UT- $\beta$-chitin's performance was significantly
\end{abstract}

Responsible editor: Guilherme L. Dotto

Electronic supplementary material The online version of this article (doi:10.1007/s11356-017-9945-x) contains supplementary material, which is available to authorized users.

Mayra F. Preto

isabella.bordon@gmail.com

1 Instituto de Biociências do Campus do Litoral Paulista, Universidade Estadual Paulista Júlio de Mesquita Filho (UNESP), Praça Infante Dom Henrique s $/ n^{\circ}$, Bairro: Parque Bitarú, São Vicente, SP 11330-900, Brazil

2 Departamento de Físico Química, Universidade de São Paulo, Instituto de Química de São Carlos (IQ-USP), Avenida do Trabalhador Sancarlense, 400, Centro, São Carlos, SP 13560790 , Brazil

3 Instituto de Pesquisas Energéticas e Nucleares (IPEN), Avenida Lineu Prestes, 2242, Cidade Universitária, São Paulo, SP 05508-000, Brazil superior to $\beta$-chitin's and chitosan's in MDO removal at salinity 0 , as well as at salinity 30 , where gladius and UT-gladius also excelled. Ultrasound treatment improved the oil removal performance of UT- $\beta$-chitin by increasing its contact surface area. This is the first report on the efficiency of gladius and UT- $\beta$-chitin for such purpose, and brought up huge possibilities and new questions that can lead to the achievement of biosorbents of great efficiency.

Keywords Squid gladius $\cdot \beta$-chitin $\cdot$ Chitosan $\cdot$ Sorbent . Marine diesel oil

\section{Introduction}

Spills of petroleum and its products represent a serious environmental and socioeconomic risk to the coastal regions (Peterson et al. 2003; Gill et al. 2012). The severity of the impacts induced by oil spills in the biota often results in mortality of many organisms and in ecological imbalances (Peterson et al. 2003). They can also affect human activities such as fishing, mariculture, tourism, and recreation (Gill et al. 2012).

About $70 \%$ of the anthropogenic inputs of petroleum to the oceans are related to oil consumption activities such as navigation (NRC 2003). Most of marine fuel oils come from fossil resources and can be divided in two types. The first, bunker oil, is generally found in large vessels. The second, marine diesel oil (MDO), is frequently used in auxiliary power generation or emergence systems of large vessels, and in main engines of small and medium vessels (Petrobrás 2013).

Sorbents are physicochemical materials frequently applied to control oil spills in water, removing contaminants through absorption and/or adsorption mechanisms (ITOPF 2012). Although synthetic sorbents have been widely used due to a 
high oil affinity, they are expensive and difficult to degrade (Teas et al. 2001; ITOPF 2012). Therefore, efforts have been made to develop biosorbents applying alternative and natural materials such as banana peels (El-Din et al. 2017), palm fibers (Abdelwahab et al. 2017), corncobs (Nwadiogbu et al. 2016), chitin (Barros et al. 2014), and chitosan (Farias et al. 2015).

The potential of chitin and chitosan to remove many classes of contaminants have been widely assessed because of their abundance of raw material, non-toxicity, easy degradation, and possibility of structural and chemical adjustment (Kumar 2000). There are many reports of the interaction of chitin, chitosan, and derivatives with different types of oil, such as soy (Fäldt et al. 1993), olive (Meyssami and Kasaeian 2005; Muzzarelli et al. 2006; Pereda et al. 2012), sunflower (Pinotti et al. 2001), palm (Ahmad et al. 2004, 2005a, 2005b, 2006), mineral (Srinivasan and Viraraghavan 2010), diesel (Bratskaya et al. 2006; Farias et al. 2015), cutting (Srinivasan and Viraraghavan 2010), biodiesel (Pitakpoolsil and Hunsom 2013), and crude oil (Sokker et al. 2011; Barros et al. 2014; Grem et al. 2013). A comparative study assessing the removal of palm oil from an industrial effluent by chitosan and two commercial and commonly used sorbents, bentonite and activated carbon, revealed chitosan as the most efficient sorbent, removing $99 \%$ of residual oil and minimizing suspended solid content (Ahmad et al. 2005a).

Chitin and chitosan are biopolymers constituted by 2 acetamido-2-deoxy-D-glucopyranose (GlcNAc) and 2-deoxy-2-amino-D-glucopyranose (GlcN) units (Campana-Filho et al. 2007). Chitin is very abundant and can be found in many organisms such as arthropods, cephalopods, algae, and others (Roberts 1992). Chitosan is rare and its main commercial forms are obtained through deacetylation of chitin in alkaline medium (Roberts 1992; Domard and Domard 2002). Considering the different arrangements of chitin in solid state $(\alpha, \beta$, and $\gamma)$, the most investigated and frequently used is the $\alpha$ polymorph (Campana-Filho et al. 2007). However, the interest in $\beta$-chitin is emerging in the last few decades (Lavall et al. 2007). Due to the arrangement of its chains, $\beta$-chitin presents a less packaged form and is chemically more accessible than the other polymorphs (Campana-Filho et al. 2007; Roberts 1992). Thereby, $\beta$-chitin is advantageous in the obtainment of chitosan, demanding a minor number of steps and reagents, besides enabling the achievement of a homogeneous product and a desired acetylation degree (Kurita et al. 1993; Tolaimate et al. 2000; Peesan et al. 2003; Chaussard and Domard 2004; Lavall et al. 2007).

Gladius, also known as pen, is a support structure of squid mantle (Yang et al. 2014). Although considered one of the richest sources of $\beta$-chitin, it is treated as fisheries residue in Brazil. Like other organic waste, it requires a specific disposal that is expensive to the producers (Lavall et al. 2007), which can lead to illegal and environmentally harmful practices.
Ibero-American countries generate about 170,000 tons/year of crustaceans and molluscs chitinous waste, totaling $12 \%$ of the world production (Goycolea et al. 2004). The inappropriate disposal of such amount of waste could results in serious environmental problems, and studies on new application for these materials are a currently demand.

The focus of the present study was to assess $\beta$-chitin and chitosan obtained from squid gladius as alternative sorbents to remove MDO from water. Due to a lack of information, it was also decided to further assess the gladius for this purpose. To improve their contact surface areas, a new approach was explored through the application of a high-intensity ultrasound treatment in $\beta$-chitin and gladius, testing if an increased surface area would improve the efficiency of these sorbents.

\section{Materials and methods}

\section{Development of sorbents}

Gladii were obtained from donation of Miami Pescados (Cananeia/SP, Brazil). The material was washed with tap and distilled water, and dried in vacuum oven (Quimis 193) for $10 \mathrm{~h}$ at $60^{\circ} \mathrm{C}$. The dry gladii were triturated in a knife mill (Marconi MA-048) and separated by their particle size using $1.68,0.5,0.25,0.18$, and $0.12 \mathrm{~mm}$ sieves. The most abundant fraction $(0.5<x<1.68 \mathrm{~mm})$ followed to deproteinization process, whereas the second most abundant $(0.25<\times<0.5 \mathrm{~mm})$ was separated to material characterization and tests with MDO.

For gladius deproteinization (Chaussard and Domard 2004), it was suspended $65.9 \mathrm{~g}$ of gladii per liter of aqueous solution of sodium hydroxide (NaOH) $1 \mathrm{M}$ (PA Synth). This mixture was stirred at $360 \mathrm{rpm}$ for $18 \mathrm{~h}$. The solid phase was separated using a sieve $(0.12 \mathrm{~mm})$, neutralized with hydrochloric acid ( $\mathrm{HCl})(\mathrm{PA}$ Synth) and washed with distilled water to remove impurities and formed salts. The obtained $\beta$-chitin was dried in oven with air circulation and renewal (Marconi MA037) for $24 \mathrm{~h}$ at $60{ }^{\circ} \mathrm{C}$. The procedures of triturating and sieving described for gladius were applied for $\beta$-chitin. The $0.5<\times<1.68 \mathrm{~mm}$ and $0.25<\times<0.5 \mathrm{~mm}$ fractions followed to deacetylation process, and material characterization and MDO removal tests, respectively.

Ultrasound-assisted deacetylation of $\beta$-chitin (Fiamingo et al. 2016) was applied to obtain chitosan. Five grams of $\beta$ chitin were suspended in $50 \mathrm{ml}$ of $40 \%(\mathrm{w} / \mathrm{w})$ aqueous solution of $\mathrm{NaOH}$ (PA Synth) and transferred to a double-walled cylindrical glass reactor $\left(\theta_{\text {int }}=3.5 \mathrm{~cm}\right)$ coupled to a circulating thermostat. This material was then submitted to pulsed ultrasonic irradiation (IP $=0.5 \mathrm{~s}$ ) by using an ultrasonic device (Hielscher Sonifer UP400S; $\nu=24 \mathrm{kHz}$ ) coupled to a sonotrode (Hielscher H22D; diameter $=22 \mathrm{~mm}$; length $=100 \mathrm{~mm}$ ), for $50 \mathrm{~min}$ at $60{ }^{\circ} \mathrm{C}$, being stirred at 
$300 \mathrm{rpm}$. The deacetylation reaction was interrupted by cooling the suspension with distilled water ice cubes. This material was then neutralized with $\mathrm{HCl}$ (PA Synth) until reaching $\mathrm{pH} 7-8$. The solid phase was isolated by filtration and extensively washed with deionized water. The material was dried in a positive pressure filter (Santonius SM 16249) for $30 \mathrm{~min}$ and in an oven with air circulation and renewal for $12 \mathrm{~h}$ at $60^{\circ} \mathrm{C}$. Chitosan was also triturated and sieved, and the fraction $0.25<\times<0.5 \mathrm{~mm}$ was characterized and applied for MDO removal tests.

In order to improve the contact surface area, a portion of gladius and $\beta$-chitin samples $(0.25<\times<0.5 \mathrm{~mm})$ was submitted to a high-intensity ultrasound treatment. In both cases, $10 \mathrm{~g}$ of sample was suspended in $150 \mathrm{ml}$ of distilled water and subjected to the ultrasound process described for chitosan for $30 \mathrm{~min}$. After this period, both ultrasound-treated gladius (UTgladius) and ultrasound-treated $\beta$-chitin (UT- $\beta$-chitin) were poured into glass ampoules, frozen, and lyophilized (lyophilizer Liotop L101). Both materials were also characterized and applied for MDO removal tests.

\section{Sorbents characterization}

External morphology of all sorbents and degrees of acetylation of $\beta$-chitin and chitosan were evaluated by scanning electron microscopy (SEM) (TableTop Hitachi TM3000) (ASTM E1382-97 2010) and nuclear magnetic resonance spectroscopy of hydrogen $\left({ }^{1} \mathrm{H}\right.$ NMR) (Bruker Avance III) (Fiamingo et al. 2016), respectively.

Gas adsorption analysis (Micromeritics ASAP 2010) was applied to determine the specific surface areas of the materials. Previously, all samples were subjected to vacuum degassing at $120^{\circ} \mathrm{C}$ for $8 \mathrm{~h}$. Measurements were obtained at $-196^{\circ} \mathrm{C}$ using nitrogen ( $\mathrm{N}_{2}$, purity $99.998 \%$ ) (White Martins). Specific surface areas were measured by BET method (Brunauer-EmmettTellet), ranging the relative pressure $\left(P / P_{0}\right)$ from 0.05 to 0.30 .

Porosity was evaluated by mercury intrusion porosimetry (Micromeritics Autopore III). Individually, samples were placed in the sample holder and submitted to vacuum, and the remaining volume of the container was filled with mercury ( $\mathrm{Hg})$ (Synth). It was measured the required pressures to $\mathrm{Hg}$ penetrate the samples, as well as the volume of $\mathrm{Hg}$ that had entered in each of those pressures, which resulted in a table of applied pressure, diameters, and volume of pores.

\section{Determination of the MDO removal capacity}

Oil removal capacity of each sorbent was determined by a density-difference approach based on Barros et al. (2014). MDO aliquots were obtain from the same samples applied in ecotoxicological assays by the project CNPq 459388/2014-2, conducted by Dra. Ágata Romero, from UNESP-CLP. Mixtures of $26 \mathrm{ml}$ of ultrapure water (Milli-Q, salinity 0 ),
$2 \mathrm{ml}$ of MDO and $2 \mathrm{~g}$ of sorbent were prepared in triplicate and stirred at $360 \mathrm{rpm}$ for $15 \mathrm{~min}$. The solid phase, composed by sorbent and sorbed oil/water, was filtrated using a nylon mesh $(0.064 \mathrm{~mm})$. Volumes of non-sorbed oil and water were estimated by comparing initial and final volumes in a graduated cylinder. Aiming to evaluate the influence of salinity, these procedures were repeated substituting ultrapure water for salinized ultrapure water (salinity 30 ). Control treatment consisted of the same steps described above without sorbent addition, determining volumes of oil and water retained by the nylon mesh (Table 1). The mean values of the controls were deducted from mean values obtained by each sorbent.

Results were described according to measures of central tendency and dispersion (minimum and maximum values, mean and standard deviation). Data were evaluated in terms of normality (Shapiro-Wilk test) and homoscedasticity (Bartlett test). In order to identify statistical differences in oil removal among sorbents due to the salinity, a two-way analysis of variance (ANOVA) was applied, followed by post hoc Tukey test, in which statistical significance was set at $p<0.05$.

\section{Results and discussion}

\section{Sorbents characterization}

Gladius presented a nonhomogeneous size and area distribution, with a mean \pm standard deviation (SD) of $777 \pm 253 \mu \mathrm{m}$ in length and $279 \pm 105 \mu \mathrm{m}$ in width. The SEM analysis revealed that gladius is composed of a rigid structure and multiple layers with irregular topography, channels, and fibers oriented along gladius major axis (Fig. 1a), corroborating with previous studies (Lavall et al. 2007; Yang et al. 2014). Ultrasound-treated gladius (UT-gladius) exhibited similar measures, presenting $702 \pm 286 \mu \mathrm{m}$ in length and $269 \pm 119 \mu \mathrm{m}$ in width. However, dilacerations in the borders of the laminar layers and the presence of many fibers can be observed (Fig. 1b). The specific surface areas of gladius $\left(2.3 \pm 0.2 \mathrm{~m}^{2} / \mathrm{g}\right)$ and UT-gladius $\left(1.9 \pm 0.2 \mathrm{~m}^{2} / \mathrm{g}\right)$ were very close, as well as their pore volumes (65 and 69\%, respectively). Gladius pore diameters were concentrated between $\approx 90-130 \mu \mathrm{m}$ with a peak at $110 \mu \mathrm{m}$, whose

Table 1 Mean values ( $\mathrm{ml}$ and \%) and standard deviation of retained oil and water obtained in controls at salinities 0 and 30

\begin{tabular}{llllll}
\hline & \multicolumn{3}{l}{ Oil } & & \multicolumn{2}{l}{ Water } \\
\cline { 2 - 3 } \cline { 5 - 6 } & $(\mathrm{mL})$ & $(\%)$ & & $(\mathrm{mL})$ & $(\%)$ \\
\hline Salinity 0 & $0.2 \pm 0.3$ & $8.3 \pm 14.4$ & & $0.7 \pm 0.6$ & $2.6 \pm 2.2$ \\
Salinity 30 & $0.2 \pm 0.3$ & $8.3 \pm 14.4$ & & $0.8 \pm 0.3$ & $3.2 \pm 1.1$ \\
\hline
\end{tabular}



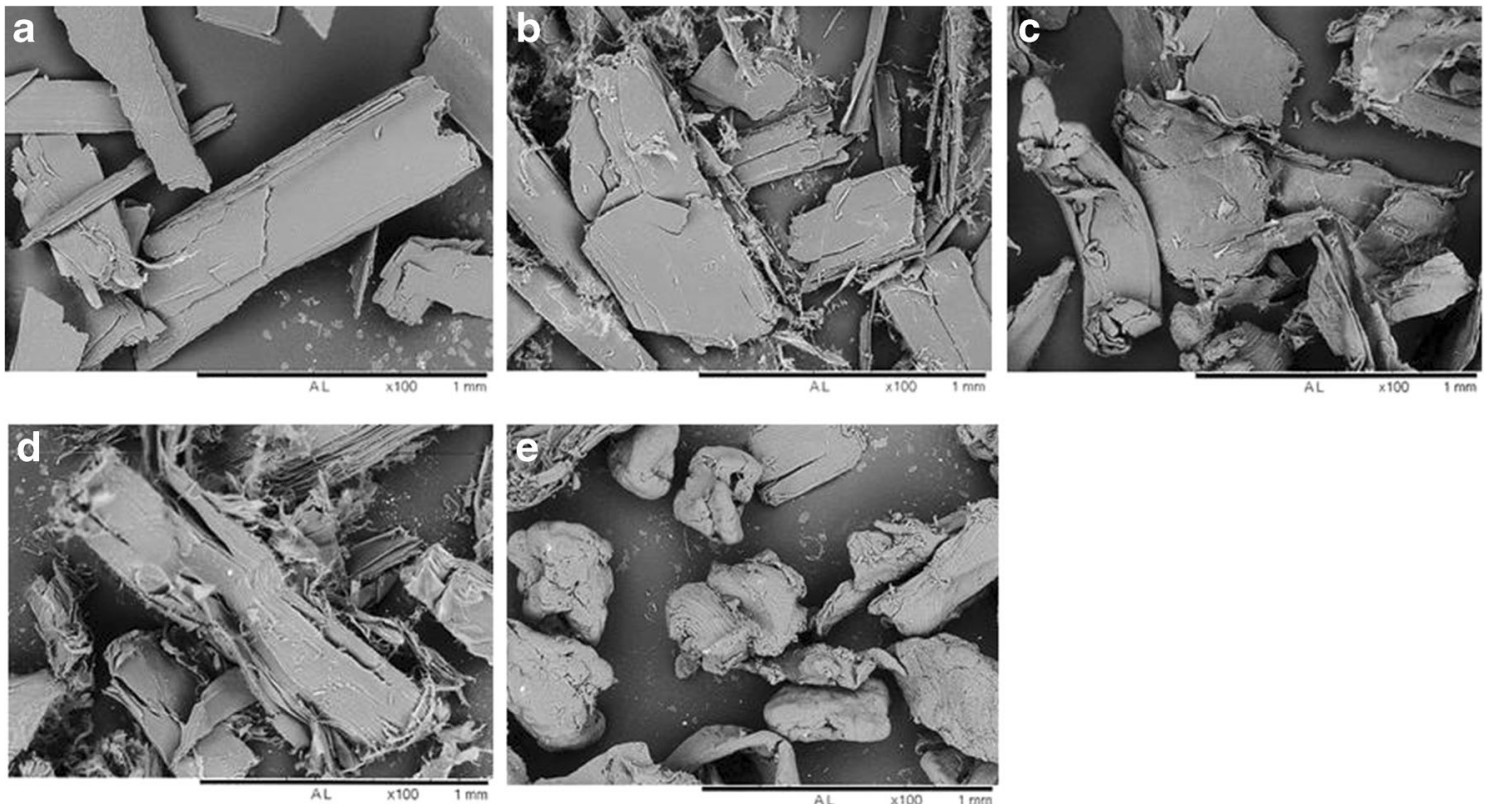

Fig. 1 Scanning electron microscopy (SEM) images in a magnification of $100 \times$ of a gladius, $\mathbf{b}$ ultrasound-treated gladius, $\mathbf{c} \beta$-chitin, $\mathbf{d}$ ultrasoundtreated $\beta$-chitin, and e chitosan

pore volume reached $0.35 \mathrm{ml} / \mathrm{g}$. UT-gladius pore diameters were around $\approx 80-150 \mu \mathrm{m}$, also with a peak at $110 \mu \mathrm{m}$ whose pore volume reached $0.4 \mathrm{ml} / \mathrm{g}$.

The structure of $\beta$-chitin was less rigid and compact than gladius (Fig. 1c). Lavall et al. (2007) assigned this patter to the extraction of the proteins from the spaces between chitin chains in the deproteinization process. The $\beta$-chitin presented $979 \pm 412 \mu \mathrm{m}$ in length and $344 \pm 99 \mu \mathrm{m}$ in width and a degree of acetylation of $70 \%$. Ultrasound treatment caused an expressive delamination in the structure of ultrasoundtreated $\beta$-chitin (UT- $\beta$-chitin), producing a great amount of fibers (Fig. 1d). This configuration of UT- $\beta$-chitin made it impossible to take its measures through SEM technique, resulting in nonrepresentative values. However, the specific surface area of UT- $\beta$-chitin $\left(8.6 \pm 0.9 \mathrm{~m}^{2} / \mathrm{g}\right)$ indicated an increase of about three times compared to $\beta$-chitin $\left(2.8 \pm 0.1 \mathrm{~m}^{2} / \mathrm{g}\right)$. UT- $\beta$-chitin also expressed an increase in pore volume (78\%) compared to $\beta$-chitin $(61 \%)$. Pore diameters of $\beta$-chitin were in a similar range to UT-gladius, and a peak at $120 \mu \mathrm{m}$ whose pore volume reached $1 \mathrm{ml} / \mathrm{g}$. UT- $\beta$ chitin, in contrast to the other sorbents, revealed a less concentrated distribution of pore diameters, ranging from $<0.01$ to more than $100 \mu \mathrm{m}$, with a concentration at $\approx 50-150 \mu \mathrm{m}$ and peak at $120 \mu \mathrm{m}$, whose pore volume achieved $0.5 \mathrm{ml} / \mathrm{g}$.

Usually applied in $\beta$-chitin deacetylation, high-intensity ultrasound is frequently related to an increase in the surface area of chitosan through the phenomenon known as cavitation (Kardos and Luche 2001). However, UT-gladius did not seem to have the same response. The rigidity provided by its composition and structure, as observed in the SEM analysis, was probably a key issue, blocking an effective penetration of water during the ultrasound treatment and preventing subsequent reactions. On the other hand, all characterization analyses clearly demonstrated an increase in the surface area of UT- $\beta$-chitin after the ultrasound procedure. The less compacted structure of $\beta$-chitin, as shown in the SEM images, should have been crucial to such results. In this sense, the high-intensity ultrasound treatment as here assessed appears to have a limitation on rigids materials, which should be better evaluated and explored. It is possible that different reaction conditions or reaction time could improve the outcomes.

Chitosan revealed predominantly circular particles (Fig. 1e) with $484 \pm 125 \mu \mathrm{m}$ in length and $332 \pm 69 \mu \mathrm{m}$ in width. Its degree of acetylation was of $40 \%$. Pore volume of chitosan (35\%) proved to be the lowest, which could suggest an inferior contact surface area. Its pore diameters presented a concentration at $\approx 90-150 \mu \mathrm{m}$ with a peak at $120 \mu \mathrm{m}$, whose pore volume reached $0.25 \mathrm{ml} / \mathrm{g}$. The degassing technique applied in the gas adsorption analysis did not allow the required removal of surface moisture from chitosan. Therefore, it was not possible to assess its specific surface area, being difficult to state the extent of the contact surface area of chitosan in relation to the other materials.

\section{Removal of marine diesel oil}

All sorbents removed MDO from water in both salinities (Table 2 and Fig. 2). At salinity 0, the performance of UT- $\beta$ chitin was significantly superior to the performances of $\beta$ chitin $(p=0.005)$ and chitosan $(p=0.03)$ in MDO removal. At salinity 30 , UT- $\beta$-chitin presented an oil removal capacity also greater than $\beta$-chitin $(p=0.0008)$ and chitosan 
Table 2 ANOVA table disposing the significance of the oil removal data obtained under salinity 0 and 30

\begin{tabular}{|c|c|c|c|c|c|c|c|}
\hline & Salinity & $\begin{array}{l}\text { Sum of } \\
\text { squares }\end{array}$ & $\begin{array}{l}\text { Degrees of } \\
\text { freedom }\end{array}$ & $\begin{array}{l}\text { Mean } \\
\text { square }\end{array}$ & $\begin{array}{l}F \\
\text { ratio }\end{array}$ & $P$ value & $\begin{array}{l}F \\
\text { crit }\end{array}$ \\
\hline \multirow{2}{*}{$\begin{array}{l}\text { Between } \\
\text { groups }\end{array}$} & 0 & 3083.33 & 4 & 770.83 & 4.62 & 0.02 & 3.48 \\
\hline & 30 & 9750 & 4 & 2437.5 & 29.25 & $1.7 \times 10^{-6}$ & 3.48 \\
\hline \multirow[t]{2}{*}{ Within groups } & 0 & 1666.67 & 10 & 166.67 & & & \\
\hline & 30 & 833.33 & 10 & 83.33 & & & \\
\hline \multirow[t]{2}{*}{ Total } & 0 & 4750 & 14 & & & & \\
\hline & 30 & $10,583.33$ & 14 & & & & \\
\hline
\end{tabular}

$(p=0.0002)$, as well as gladius $(p=0.0008$ and $p=0.0002$, respectively) and UT-gladius ( $p=0.005$ and $p=0.0008)$ (Table 3).

As indicated by the characterization analyses, the ultrasound treatment did not result in an improvement in MDO removal of UT-gladius. Gladius removed 58 and $92 \%$ of the total amount of oil at salinities 0 and 30, respectively, while UT-gladius removed 50 and $83 \%$, with no significant difference between these sorbents within the salinity treatments (Fig. 2).

On the other hand, $\beta$-chitin removed 33 and $42 \%$ of the total amount of MDO at salinities 0 and 30, respectively, while UT- $\beta$-chitin reached 75 and $92 \%$, with significant differences within salinity treatments (Table 3 ). Considering the results of characterization analyses and MDO removal tests, the ultrasound treatment has increased the available surface area of UT- $\beta$-chitin, which resulted in a significant improvement of its MDO removal performance compared with its source material ( $\beta$-chitin). Reports on other sorbents also detected a direct relationship between increase in available surface area and enhancement in oil removal (Ahmad et al. 2004, 2005a; Srinivasan and Viraraghavan 2010; Farias et al. 2015; Grem et al. 2013).
As well as $\beta$-chitin, chitosan presented a low performance, removing 42 and $33 \%$ of the total amount of MDO at salinities 0 and 30, respectively. There is a wide literature on the removal of different types of oil by chitosan. Many authors attribute its competence to the positive character of its amino groups, that could either neutralize negatively charged oils (Ahmad et al. 2004, 2005a; Srinivasan and Viraraghavan 2010; Sokker et al. 2011; Barros et al. 2014) as attract slightly polar molecules present in fossil fuels (Grem et al. 2013; Ferreira et al. 2009). The cyclic conformation of carbons in the main chain of chitosan would also be responsible for a low polarity that could attract hydrocarbon compounds through Van der Waals interactions (Grem et al. 2013). In this sense, chitosan was the sorbent with the highest expectations, and the reasons behind such results are important to stand out.

A lower surface area could be related to the performance of chitosan. However, even chitosan exhibiting the lowest pore volume, without other data to give support (e.g., specific surface area) it is not possible to prove. Nevertheless, it should be considered that, in water, uncharged chitosan units may attract each other through hydrogen bonds and hydrophobic interactions (Philippova
Fig. 2 Performances of marine diesel oil (MDO) removal of each sorbent at salinities 0 and 30

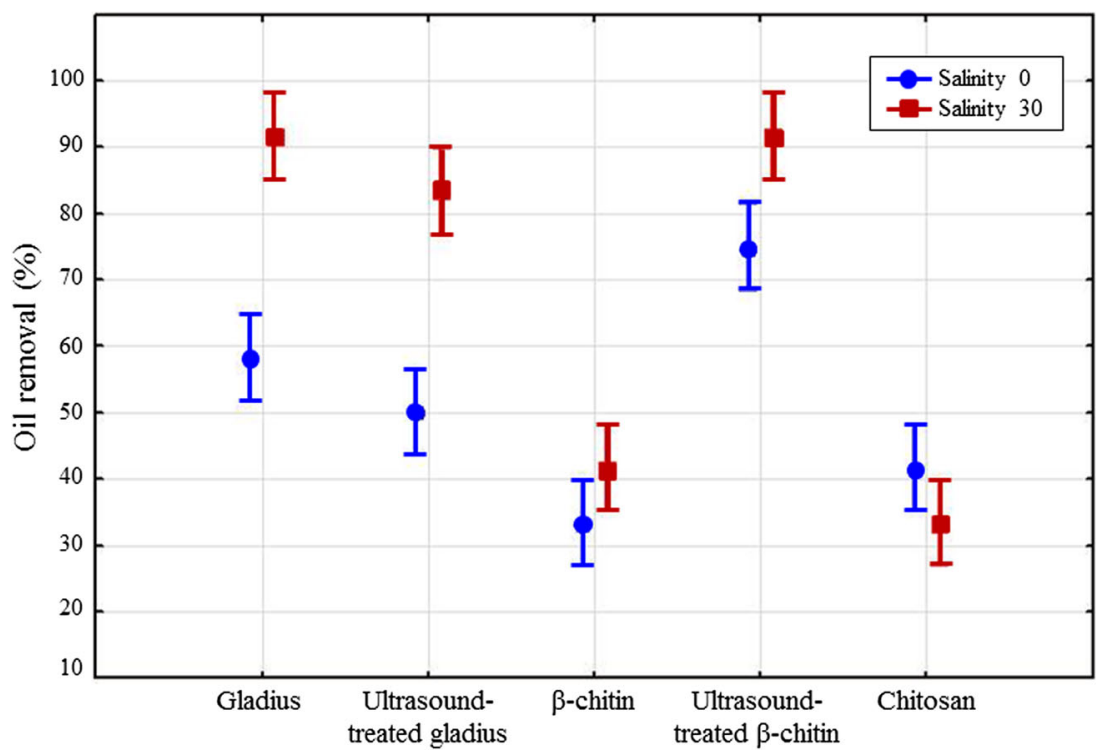


Table 3 Statistical significant differences (Tukey test, $p<0.05$ ) between MDO removal performances of biosorbents gladius (1 and 6), ultrasoundtreated gladius ( 2 and 7 ), $\beta$-chitin ( 3 and 8 ), ultrasound-treated $\beta$-chitin ( 4 and 9 ), and chitosan ( 5 and 10$)$ under salinities 0 (sorbents numbered from 1 to 5) and 30 (from 6 to 10 )

\begin{tabular}{|c|c|c|c|c|c|c|c|c|c|c|}
\hline & (1) & (2) & (3) & (4) & (5) & (6) & (7) & (8) & (9) & (10) \\
\hline (1) & & 0.994119 & 0.223457 & 0.713319 & 0.713319 & 0.039973 & 0.223457 & 0.713319 & 0.039973 & 0.223457 \\
\hline (2) & 0.994119 & & 0.713319 & 0.223457 & 0.994119 & 0.005762 & 0.039973 & 0.994119 & 0.005762 & 0.713319 \\
\hline (3) & 0.223457 & 0.713319 & & 0.005762 & 0.994119 & 0.000267 & 0.000896 & 0.994119 & 0.000267 & 1.000000 \\
\hline (4) & 0.713319 & 0.223457 & 0.005762 & & 0.039973 & 0.713319 & 0.994119 & 0.039973 & 0.713319 & 0.005762 \\
\hline$(5)$ & 0.713319 & 0.994119 & 0.994119 & 0.039973 & & 0.000896 & 0.005762 & 1.000000 & 0.000896 & 0.994119 \\
\hline (6) & 0.039973 & 0.005762 & 0.000267 & 0.713319 & 0.000896 & & 0.994119 & 0.000896 & 1.000000 & 0.000267 \\
\hline (7) & 0.223457 & 0.039973 & 0.000896 & 0.994119 & 0.005762 & 0.994119 & & 0.005762 & 0.994119 & 0.000896 \\
\hline (8) & 0.713319 & 0.994119 & 0.994119 & 0.039973 & 1.000000 & 0.000896 & 0.005762 & & 0.000896 & 0.994119 \\
\hline (9) & 0.039973 & 0.005762 & 0.000267 & 0.713319 & 0.000896 & 1.000000 & 0.994119 & 0.000896 & & 0.000267 \\
\hline (10) & 0.223457 & 0.713319 & 1.000000 & 0.005762 & 0.994119 & 0.000267 & 0.000896 & 0.994119 & 0.000267 & \\
\hline
\end{tabular}

and Korchagina 2012). Likewise, a high concentration of acetyl groups in $\beta$-chitin can result in a similar behavior (Pedroni et al. 2003). In this sense, it is possible that an aggregation of $\beta$-chitin and chitosan units may have caused a reduction in their contact surface areas and influenced the performances.

Ahmad et al. (2004) tested the effect of $\mathrm{pH}$ on the performance of chitosan in oil removal. At $\mathrm{pH}$ range of $3-6$, chitosan removed $80-100 \%$ of the total amount of oil present in the solution. However, at neutral $\mathrm{pH}$ range its performance dropped to $40 \%$. Because the amino groups present a $\mathrm{pKa}$ of 6-6.5, at neutral $\mathrm{pH}$ chitosan does not present a strongly cationic nature (Dash et al. 2011), and its ability to attract other molecules is affected. Considering that the ultrapure water used in the MDO removal tests was at neutral $\mathrm{pH}$, it is possible that the performance of chitosan was also affected by deprotonation of its amino groups.

\section{Water retention and salinity influence}

Sorbents exhibited different propensities to water retention (Fig. 3). Chitosan, $\beta$-chitin and UT- $\beta$-chitin retained large amounts of water during the tests of MDO removal in comparison with gladius and UT-gladius. In fact, water retention is a disadvantage in many natural sorbents (Ali et al. 2012), being often associated with a low hydrophobicity and a low performance in oil removal (Likon et al. 2013). It is well known that both $\beta$-chitin and chitosan obtained from gladius can retain large amounts of moisture, especially $\beta$-chitin due to its high acetylation degree (Chandumpai et al. 2004) and molecular arrangement (Kurita et al. 1993). It is possible that the performances of $\beta$-chitin and chitosan in MDO removal were also related to their water retention rate. Even though UT- $\beta$-chitin retained large amounts of water, other factors, such as its large surface area, may have had a greater influence on its performance than water retention.
Fig. 3 Mean values and standard deviation of water retention of each sorbent

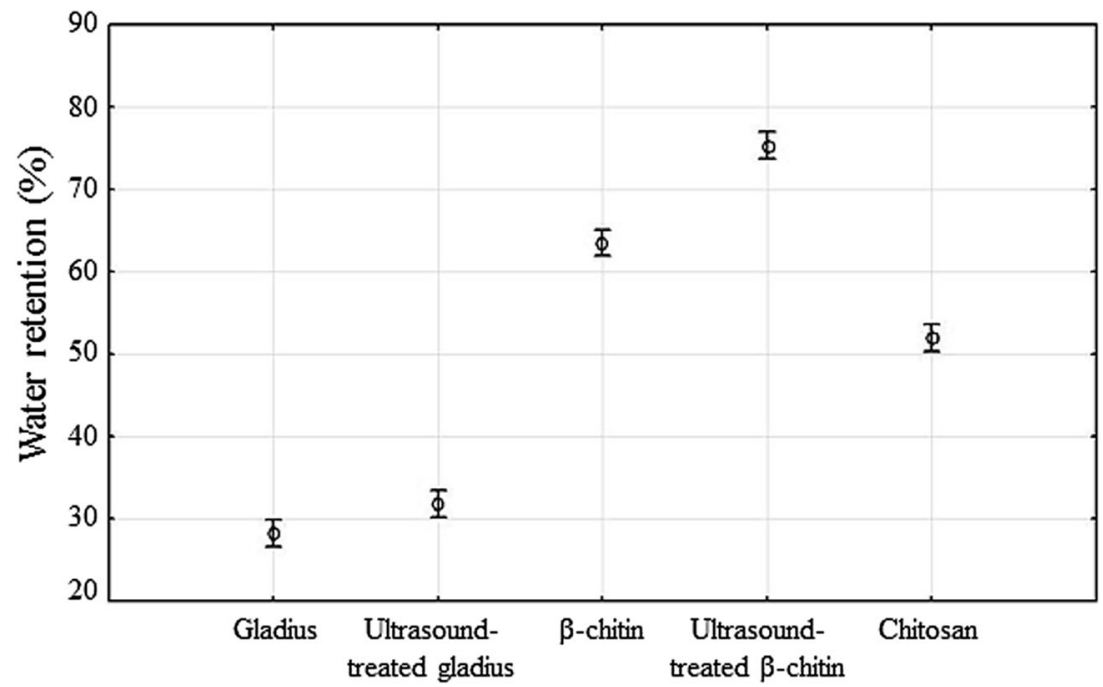




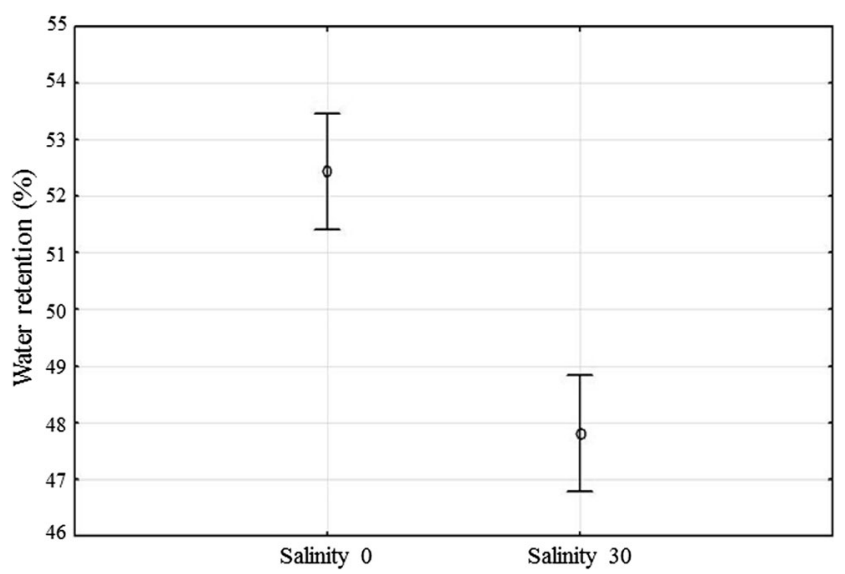

Fig. 4 Mean values and standard deviation of water retention of the set of sorbents at salinities 0 and 30

It was identified a relationship between water retention by the set of sorbents and salinity, which presented a greater tendency of water retention at salinity 0 than at 30 (Fig. 4). In fact, dissolved salts in water influence water retention by polymers. An increase in salts concentration often results in a decrease in water retention by these materials (Coelho, unpublished results), which corroborates the trend observed here. Salinity also demonstrated to have an influence in MDO removal, as evidenced in Tables 2 and 3. Both gladius and UTgladius presented a significant improvement in their oil uptake when subjected to salinity $30(p<0.03)$. It is possible that the relationship between the decrease in water retention and the increase in oil removal at high salinity, as observed in gladius and UT-gladius, resides in a type of sorbent-oil interaction in which water and oil compete for the same spots in the contact surface area of the sorbent.

\section{Conclusions}

Oil removal was governed by the interaction of a set of factors, such as salinity of the medium, available contact surface area and water retention of the sorbents. All tested sorbents were able to remove MDO from fresh and salt water, presenting potentialities and characteristics to be further explored. Gladius is a material of simple and cheap processing, with abundant raw material provided from waste, and presented great performance. This unstudied and underestimated material, as well as ultrasound-treated $\beta$-chitin (UT- $\beta$-chitin), demonstrated great potential as oil sorbents and are highly recommended for future investigations. Chitosan and $\beta$-chitin presented limitations under the tested conditions. Although ultrasound-treated gladius (UT-gladius) did not properly response to the treatment, the high-intensity ultrasound demonstrated great potential to improve oil uptake of UT- $\beta$-chitin by increasing its available contact surface area, and the best reaction conditions of this treatment and applicability in other materials should be further explored. Analyses on the influence of variables such as exposure time, stirring speed, sorbent dosage, and particle size would improve the use of these materials as biosorbents.

Acknowledgements The authors acknowledge the financial support from the São Paulo Research Foundation (FAPESP, 2015/10362-2) for this research. Also, authors would like to thank Conselho Nacional de Desenvolvimento Científico e Tecnológico $(\mathrm{CNPq})$ for the financial support of the project CNPq 459388/2014-2.

\section{References}

Abdelwahab O, Nasr SM, Thabet WM 2017. Palm fibers and modified palm fibers adsorbents for different oils. Alexandria engineering journal. 1-7

Ahmad AL, Sumathi S, Hameed BH (2004) Chitosan: a natural biopolymer for the adsorption of residue oil from oily wastewater. Adsorpt Sci Technol 22(1):75-88

Ahmad AL, Sumathi S, Hameed BH (2005a) Residual oil and suspended solid removal using natural adsorbents chitosan, bentonite and activated carbon: a comparative study. Chem Eng J 108(1):179-185

Ahmad AL, Sumathi S, Hameed BH (2005b) Adsorption of residue oil from palm oil mill effluent using powder and flake chitosan: equilibrium and kinetic studies. Water Res 39(12):2483-2494

Ahmad AL, Sumathi S, Hameed BH (2006) Coagulation of residue oil and suspended solid in palm oil mill effluent by chitosan, alum and PAC. Chem Eng J 118(1-2):99-105

Ali N, El-Harbawi M, Jabal AA, Yin C-Y (2012) Characteristics and oil sorption effectiveness of kapok fibre, sugarcane bagasse and rice husks: oil removal suitability matrix. Environ Technol 33(4):481-486

ASTM E1382-97 (2010) Standard test methods for determining average grain size using semiautomatic and automatic image analysis. ASTM International, West Conshohocken

Barros F, Vasconcellos L, Carvalho T, Nascimento R (2014) Removal of petroleum spill in water by chitin and chitosan. Orbital - The Electron J Chem 6(1):70-74

Bratskaya S, Avramenko V, Schwarz S, Philippova I (2006) Enhanced flocculation of oil-in-water emulsions by hydrophobically modified chitosan derivatives. Colloids Surf A Physicochem Eng Asp 275(1-3):168-176

Campana-Filho SP, Britto D, Curti E, Abreu FR, Cardoso MB, Battisti MV, Sim PC, Goy RC, Signini R, Lavall RL (2007) Extração, estruturas e propriedades de $\alpha$ - e $\beta$-quitina. Química Nova 30(3): 644-650

Chandumpai A, Singhpibulporn N, Faroongsarng D, Sornprasit P (2004) Preparation and physico-chemical characterization of chitin and chitosan from the pens of the squid species, Loligo lessoniana and Loligo formosana. Carbohydr Polym 58(4):467-474

Chaussard G, Domard A (2004) New aspects of the extraction of chitin from squid pens. Biomacromolecules 5(2):559-564

Coelho J, Unpublished results. Aplicação de doses do polímero hidratassolo sobre a capacidade de retenção de água de solos e desenvolvimento da beterraba, em condições salinas. Unpublished results. Master Dissertation, Federal Rural University of Pernambuco, Brazil

Dash M, Chiellini F, Ottenbrite R, Chiellini E (2011) Chitosan - a versatile semi-synthetic polymer in biomedical applications. Prog Polym Sci 36(8):981-1014

Domard A, Domard M (2002) Chitosan: structure-properties relationship and biomedical applications. In: Dumitriu S (ed) Polymeric 
biomaterials, Second edn. Revised and Expanded, Marcel Dekker Inc., New York, pp 187-212

El-Din GA, Amer AA, Malsh G, Hussein M (2017) Study on the use of banana peels for oil spill removal. Alex Eng J:1-8

Fäldt P, Bergenståhl B, Claesson P (1993) Stabilization by chitosan of soybean oil emulsions coated with phospholipid and glycocholic acid. Colloids Surf A Physicochem Eng Asp 71(2):187-195

Farias P, Aragão D, Farias M, Correia L, Carvalho T, Aguiar J, Vieira R (2015) Natural and cross-linked chitosan spheres as adsorbents for diesel oil removal. Adsorpt Sci Technol 33(9):783-792

Ferreira V, Rocha D, Silva F (2009) Potentiality and opportunity in the chemistry of sucrose and other sugars. Química Nova. 32(3):623-638

Fiamingo A, Delezuk JAM, Trombotto S, David L (2016) Extensively deacetylated high molecular weight chitosan from the ultistep ultrasound-assisted deacetylation of beta-chitin. Ultrason Sonochem 32:79-85

Gill DA, Picou JS, Ritchie LA (2012) The Exxon Valdez and BP oil spills: a comparison of initial social and psychological impacts. Am Behav Sci 56(1):3-23

Goycolea F, Agulló E, Mato R (2004) Fuentes y procesos de obtención. In: Abram AP (ed) Quitina y quitosana: obtención, caracterización y aplicaciones. Pontifical Catholic University of Peru, Lima, pp 106-154

Grem I, Lima B, Carneiro W, Queirós Y, Mansur C (2013) Chitosan microspheres applied for removal of oil from produced water in the oil industry. Polímeros 23(6):705-711

International Tanker Owners Pollution Federation (ITOPF) (2012) Use of sorbent materials in oil spill response-technical information paper. Eight volume, Impact PS \& Design Limited, Canterbury

Kardos N, Luche J-L (2001) Sonochemistry of carbohydrate compounds. Carbohydr Res 332(2):115-131

Kumar MNVR (2000) A review of chitin and chitosan applications. React Funct Polym 46(1):1-27

Kurita K, Tomita K, Tada T, Ishili S, Nishimura S, Shimoda K (1993) Squid chitin as a potential alternative chitin source: deacetylation behavior and characteristic properties. J Polym Sci A Polym Chem 31(2):485-491

Lavall RL, Assis OBG, Campana-Filho SP (2007) Beta-chitin from the pens of Loligo sp.: extraction and characterization. Bioresour Technol 98(13):2465-2472

Likon M, Remškar M, Ducman V, ك̌vegl F (2013) Populus seed fibers as a natural source for production of oil super absorbents. J Environ Manag 114:158-167

Meyssami B, Kasaeian A (2005) Use of coagulants in treatment of olive oil wastewater model solutions by induced air flotation. Bioresour Technol 96:303-307

Muzzarelli R, Orlandini F, Pacetti D, Bosellic E, Fregac N, Tosib G, Muzzarelli C (2006) Chitosan taurocholate capacity to bind lipids and to undergo enzymatic hydrolysis: an in vitro model. Carbohydr Polym 66:363-371

National Research Council (NRC) (2003) Oil in the sea III: inputs, fates, and effects, Third edn. National Academies Press, Washington, DC

Nwadiogbu JO, Ajiwe VIE, Okoye PAC (2016) Removal of crude oil from aqueous medium by sorption on hydrophobic corncobs: equilibrium and kinetic studies. J Taibah Univ Sci 10(1):56-63

Pedroni V, Schulz P, Gschaider M, Andreucetti N (2003) Chitosan structure in aqueous solution. Colloid Polym Sci 282(1):100-102

Peesan M, Rujiravanit R, Supaphol P (2003) Characterization of betachitin/poly(vinyl alcohol) blend films. Polym Test 22(4):381-387

Pereda M, Amica G, Marcovich N (2012) Development and characterization of edible chitosan/olive oil emulsion films. Carbohydr Polym 87(2):1318-1325

Peterson CH, Rice SD, Short JW, Esler D, Bodkin JL, Ballachey BE, Irons DB (2003) Long-term ecosystem response to the Exxon Valdez oil spill. Science 302(5653):2082-2086

Petróleo Brasileiro SA - Petrobrás (2013) Combustíveis Marítimos: Informações Técnicas. Petrobrás, Brazil. http://sites.petrobras.com. $\mathrm{br} / \mathrm{minisite/assistenciatecnica/public/downloads/manual-tecnico-}$ combustiveis-maritimos-asistencia-tecnica-petrobras.pdf. Accessed 2 April 2017

Philippova O, Korchagina E (2012) Chitosan and its hydrophobic derivatives: preparation and aggregation in dilute aqueous solutions. Polymer Science Series A 54(7):552-572

Pinotti A, Bevilacqua A, Zaritzky N (2001) Comparison of the performance of chitosan and a cationic polyacrylamide as flocculants of emulsion systems. J Surfactant Deterg 4(1):57-63

Pitakpoolsil W, Hunsom M (2013) Adsorption of pollutants from biodiesel wastewater using chitosan flakes. J Taiwan Inst Chem Eng 44(6): 963-971

Roberts G (1992) Chitin chemistry. McMillan Press Ltd, London

Sokker H, El-Sawy N, Hassan M, El-Anadouli B (2011) Adsorption of crude oil from aqueous solution by hydrogel of chitosan based polyacrylamide prepared by radiation induced graft polymerization. $\mathrm{J}$ Hazard Mater 190(1):359-365

Srinivasan A, Viraraghavan T (2010) Oil removal from water using biomaterials. Bioresour Technol 101(17):6594-6600

Teas C, Kalligeros S, Zanikos F, Stournas S, Lois E, Anastopoulos G (2001) Investigation of the effectiveness of absorbent materials in oil spills clean up. Desalination 140(3):259-264

Tolaimate A, Desbrieres J, Rhazi M, Alagui A, Vincendom M, Votteri P (2000) On the influence of the deacetylation process on the physiochemical characteristics of chitosan from squid chitin. Polymer 41(7):2463-2469

Yang F, Peters R, Dies H, Rheinstädter M (2014) Hierarchical, selfsimilar structure in native squid pen. Soft Matter 10(30):5541-5549 